\title{
HOW TO SELECT POTENTIAL SITES OF COMMUNITY IMPORTANCE TO THE NATURA 2000 NETWORK: THE ISSUE OF CRITERIA
}

\author{
STANISŁAW TWOREK*, MAŁGORZATA MAKOMASKA-JUCHIEWICZ, GRZEGORZ \\ CIERLIK
}

Institute of Nature Conservation, Polish Academy of Sciences, Al. Mickiewicza 33, 31-120 Kraków, Poland; e-mail: tworek@iop.krakow.pl

* Author for correspondence

\begin{abstract}
Tworek S., Makomaska-Juchiewicz M., Cierlik G.: How to select potential sites of community importance to the NATURA 2000 network: the issue of criteria. Ekológia (Bratislava), Vol. 33, No. 2, p. 127-137, 2014

In this paper, on the basis of experience gained at the elaboration of the Proposal of Natura 2000 network in Poland, we analyse the usefulness of criteria recommended in Annex III of the Habitats Directive (HD) for selecting proposed Sites of Community Importance (pSCI), i.e. potential Special Areas of Conservation. These are sites important for conservation of habitat types and species (except for birds), listed in Annexes I and II of the HD. The recommendations should allow arriving at the estimates of relative value of the selected areas vis-à-vis the national resources of each habitat type and species. These are, however, neither objective and quantified nor easy to apply criteria; because most of them rely on best expert judgement, which is subjective to a great extent. Moreover, the practical usefulness of the criteria is related to the level of knowledge of the distribution and size of resources of the habitat types and species of European importance. Our experience of selecting pSCI at national level indicates that this stage of work calls for more precise criteria than these recommended in the HD. We present our proposal of domestic criteria, which make easier the preliminary selection of pSCI that were tested in work with local experts responsible for regional proposals of sites to the Natura 2000 network in Poland. Because of the far-reaching consequences entailing the designation of Natura 2000, we would like to encourage a widespread discussion on criteria for selecting pSCI.
\end{abstract}

Key words: criteria for pSCI selection, European importance, best expert judgement, Habitats Directive, Natura 2000, Poland.

\section{Introduction}

The establishment of the European Ecological Network - Natura 2000 is one of the most important tasks in the protection of biological diversity facing by the European Union Member States (Rojas-Briales, 2000; Makomaska-Juchiewicz, Tworek, 2003). The network is to protect natural habitat types endangered and/or representative of the biogeographical regions 
of the European Community as well as endangered and rare plant and animal species living within EU boundaries. One of the two subsystems of the network are sites selected on the basis of Council Directive 92/43/EEC (Habitats Directive, 'HD'), which the Member States submit as the so-called proposed (or eligible) Sites of Community Importance (pSCI), and then - after they are approved by the European Commission - designate as Special Areas of Conservation (SAC).

The pivotal issue is to apply proper criteria at the stage of selection of pSCI as well as at the stage of verification of the sites already proposed for inclusion. In accordance with the HD, the basis of site selection are Annexes I and II, i.e. the lists of natural habitat types and species, whose conservation requires designation of SAC, whereas Annex III of the HD provides the criteria (or rather recommendations) for the designation. Applying these should help to determine whether the area, where such a habitat or species occurs, is indeed important for its conservation. In other words, the criteria should allow arriving at the estimates of relative value of the selected areas vis-à-vis the national resources of each habitat type and species. These are neither objective and quantified nor easy to apply criteria; because some of them rely on best expert judgement, which is subjective to a great extent. Moreover, the practical usefulness of the criteria is related to the level of knowledge of the biological diversity of the country, and most of all the distribution and resources of the habitat types and species of European importance (Dimitrakopoulos et al., 2004).

In this paper, against the background of our own experience with developing the design of Natura 2000 network in Poland, we analyse the usefulness of criteria for selecting pSCI, recommended in the HD. We also present and discuss our proposals of additional criteria facilitating preliminary selection of an area as a pSCI, on the basis of its natural values. Because of the far-reaching consequences entailing the designation of Natura 2000 sites, we would like to encourage a widespread discussion on pSCI selection criteria in general.

\section{Criteria for selecting pSCI and designation of SAC following the HD Site assessment criteria for natural habitat types listed in Annex I (Annex III, Stage 1A)}

As regards the natural habitat types, the most important criterion is a degree of representativeness of the natural habitat type on the site, assessed using a four-grade ranking system (excellent, good or significant representativeness, non-significant presence). This should be regarded as showing how typical a habitat type is when compared with a pattern described in the Interpretation Manual of European Union Habitats (Interpretation Manual of European Union Habitats, 2003). It is a subjective assessment, calling for profound expert knowledge, and difficult to apply in countries where habitat types have been adopted as a new object of conservation and the process of identifying them in the context of domestic phytosociological knowledge has not been completed yet. If the representativeness of a habitat type in a given area has been assessed as 'non-significant' it is disqualified as a basis for selection and other criteria need not be applied. The next criteria for habitat types pertain to the relative area of the site covered by the natural habitat type in relation to the total area covered by that natural habitat type within natural territory, and also to the degree of conservation of the structure and functions of the natural habitat type concerned (also taking into account resto- 
ration possibilities). The former is a rough estimate in three intervals of relative size $(0-2 \%$, $2-15 \%, 15-100 \%)$. Even such rough estimates require, however, the knowledge of national resources (areas) of each habitat type. In Poland such data are not available for most habitat types and no mapping thereof has been carried out. As a result, for many pSCI, for which no phytosociological maps are available, the very assessment of surface occupied by a given habitat type might have carried serious error, particularly in the case of habitats naturally occupying small patches (e.g. xerothermic grasslands).

Again, as in the case of representativeness, the assessment pertaining to the structure and function of a habitat type is another subjective expert judgment. It consists of three independent sub-criteria, but the ultimate assessment is a resultant of the three values (all evaluated against a three-grade scale). The first element is the degree of structure conservation (excellent structure, structure well conserved, average or partially degraded structure); i.e. the present state of physiognomy of the habitat is evaluated by a comparison with either the existing manual on natural habitat types (Interpretation Manual of European Union Habitats, 2003), or with the same type of habitat in other areas. The second sub-criterion includes the evaluation of the degree of conservation of function (taking into account the present dynamic stage and the developmental trends in the community) which, in fact, involves the determination of the prospects of the habitat type to maintain its structure for the future, given possible unfavourable influences and possible conservation efforts. These prospects are evaluated in a three-point scale: excellent, good and average or unfavourable. The third sub-criterion pertains to the possibilities of restoration (easy, possible with an average effort, difficult or impossible). Its application requires expert knowledge of structure and function of a given habitat type, specific conservation plans and measures needed to restore it, and arriving at cost estimates evaluated against the efficiency of restoring the habitat from the viewpoint of nature conservation, taking into account the degree of threat to the given habitat type and its rarity.

\section{Site assessment criteria for species listed in Annex II (Annex III, Stage 1B)}

The most important criterion is the size and density of the population of the species present on the site in relation to the population present within national territory. This criterion is objective and easy to use, provided that the suitable data are at hand. However, in Poland (and most likely in many other countries too) quantitative data pertaining to national populations, but above all the local populations for the overwhelming majority of species (particularly fishes and invertebrates) are lacking. On one hand, the proposed estimates for relative size of population, suggested in Annex III ( $>15-100 \%,>2-15 \%, 0-2 \%$, non-significant population) should then facilitate the assessment. On the other hand, however, they did not differentiate local populations well enough, particularly in the case of relatively numerous and widely distributed species. If such species do not develop concentrations, their relative abundance in the area usually fall into $0-2 \%$ bracket. Evaluating a relative population of a species as being 'non-significant', disqualifies it as a basis for selecting a site and thus there is no point in applying any other criteria. It is not clear, however, when the lowest estimate (non-significant population) should be applied, when the next estimate 
falls into the range from 0 to $2 \%$. As a result, the differentiation between these two evaluations is subjective and poses many difficulties. The next criterion for species is the evaluation of the degree of conservation of the features of the habitat which are important for the species and their potential restoration to natural state. The analysis covers the structure of the habitat and the selected abiotic parameters thereof which are important from the viewpoint of the biology of the species and among them particularly these which affect the population dynamics, again using a three-point scale: elements (of the habitat) in excellent condition; elements well conserved; elements in average or partially degraded condition. In the case when the elements of the habitat are average or partially degraded, the chances of their restoration are evaluated additionally, also on a three-point scale (restoration easy, restoration possible with average effort, restoration difficult or impossible). As a result of applying these sub-criteria, the state of conservation can be assessed as: conservation excellent, good conservation, average or reduced conservation. This criterion is again a subjective evaluation by experts, which is the easiest when a strong local population of the species is present, and then for the sake of simplifying the issue, it may be assumed that its presence testifies to at least good conservation of the habitat of the species.

The third criterion related to species pertains to the isolation of the population present on the site in relation to the natural range of the species. The degree of isolation is an approximate measure of the contribution of a given population to the genetic diversity of the species (to put it in a simplified form: the more a population is isolated, the greater is its contribution to genetic diversity of the species) and how much it is prone to extinction. Again, the evaluation is made against a three-point scale: (population) almost isolated; not-isolated but on margins of area of distribution; not-isolated within an extended distribution range. In theory, this grading should be quite simple. In practice, however, applying the criterion is mostly subjective because in the case of rarer and relatively less mobile species, whose distribution is poorly known it is not always simple to distinguish between the isolated or almost isolated population, and the not-isolated population within an extended distribution range. The ultimate distinction will thus have to be made again by an expert.

\section{Global assessment}

Applying the abovementioned criteria should lead to the derivation of the global assessment of the value of a given site for the natural habitat types or species. The assessment should also include several additional factors which could affect the conservation of a habitat type or species, e.g. existing or potential threats, the present protection status of the area (e.g. of a nature reserve or national park). The global assessment is given under a three-point scale as 'excellent', 'good' or 'significant'. The assessment is again based on expert judgment. There is no 'key' which would lead from the sub-criteria to the final assessment. It seems advisable for teams committed in selecting the pSCI should decide themselves on combinations of subcriteria leading to the global assessment. Truly, this might not add more objectivity' to the assessment but will somewhat simplify this important stage of work.

Theoretically, all these areas which obtained at least 'significant' value of the global assessment for the conservation of a habitat type or a species, listed in relevant Annexes 
of the HD, may be included in the Natura 2000 network. Thus, by applying the procedure based on the above criteria (mostly subjective evaluations) and dealing with the more widespread types of habitat and abundant species, we may end up with an enormous pool of areas covering a significant portion of the national territory.

\section{Other criteria}

Apart from the aforementioned specific criteria, listed separately for habitat types and species (in the Stage 1 of Annex III of the HD), when the final lists of SAC to be submitted to the European Commission, the considerations may include additional recommendations listed in Annex III HD, Stage 2, which refer to the assessment of the Community importance of the sites included in the national lists, as well as provisions of other Articles of the HD:

- Priority status of a habitat type or a species (Annex III, Stage 2. para 1). Our prime concern should focus on placing in the network, above all, the areas important to the conservation of priority habitats and species, i.e. these for protection of which the Community bears particular responsibility. Such areas will be approved as SCIs by the experts of the Commission before any other areas. It does not mean, however, that any area where a priority habitat or species has been found must necessarily be designated to the network (cf. criteria described in Annex III, Stage $1 \mathrm{~A}, \mathrm{~B}$ ).

- Geographical range of a habitat type or a species (Articles 1e and 1i HD). Maintaining the geographical range of habitat types and species is necessary in order to secure their 'favourable' conservation status. For this reason, the areas selected for the particular types of habitats and individual species should reflect the distributions of their stations in a given country.

- Particular responsibility of a given country for the conservation of a habitat type or species (Article 3.2 HD). Each of the Member States has particular responsibility for certain habitat types and species because it is on its territory where a significant percentage of the European resources of these habitats or species occur. These might be extraordinarily rare or even endemic habitats or species, occurring solely or almost solely in a given country, as well as species or habitats of wide distribution, occurring in large numbers or covering large surfaces. If the resources of a habitat or species in a given country are markedly more abundant then in other Member States, then both the number and size of the areas selected for this habitat or species should be correspondingly greater.

- Occurrence of greater number of habitat types and/or species (III HD; Stage 2, para $2 \mathrm{~d}$ ). If one and the same area is important to the conservation of a greater number of habitat types and/or habitats of species, this elevates its rank, because the HD emphasizes the protection of biodiversity. This criterion usually applies to large areas, as the number of habitat types and/or species is largely a function of the size of the area where they occur (Schluter, Ricklefs, 1993; Rosenzweig, 1995; He, Legendre, 2002).

- Location of the area (Annex III HD; Stage 2, para 2b). If the area is situated on migration routes of species listed in Annex II HD or in a border zone where it is a part of an ecosystem extended on both sides of a borderline between Member States, this situation elevates its rank. 
Most of the above general criteria are the criteria used by the European Commission when assessing the Community importance of the sites included in the national lists (Annex III, Stage 2). In our opinion, applying these criteria during pSCI selection at the national level might also be useful. The criteria can be used when, for variety of reasons, there is a need of choosing areas from among of those which, under specific criteria, were given only 'significant' global assessment of importance to the protection of particular species or habitat type.

\section{Proposed domestic criteria for pSCI in Poland}

In Poland, the main stage of selecting proposals of sites for inclusion in the network was based on the work done in the Voivodship Implementation Teams (VITs) (Baranowski, 2003), whose competences matched the administrative divisions of Poland then in force. It was presumed that the VIT members, associated with individual voivodships, have the most relevant knowledge pertaining to habitat types and species covered in Annexes I and II of the $\mathrm{HD}$ and to the areas with valuable natural features which might be potential elements of the network. While working in the team of experts leading the effort, we developed a set of criteria for VITs in preliminary submission of areas as pSCI (its final inclusion in a so-called pSCI expert proposal has been decided by a steering group from the Institute of Nature Conservation PAS). The criteria were developed on the basis of the aforementioned criteria, recommended in Annex III HD and referred to in some of its Articles. Moreover, we suggested a criterion based on rarity and high level of threat in Poland, to a habitat type or species listed in Annexes I and II HD. Because the resources of some types of habitats of Annex I HD and some species of Annex II HD vary markedly between the Member States, we have decided that the particular emphasis should be placed on the areas whose habitats and species are rare and endangered in the country. The selection of these species was based on a current Red Books covering plant and animal species (CR and EN categories, endemites irrespective of the category of threat - Głowaciński, 2001; Głowaciński, 2002; Kaźmierczakowa, Zarzycki, 2001), and the selection of habitat types - on the current knowledge of their distribution in Poland (Herbich, 2004).

We have decided that for an area to be indicated by VIT as a potential pSCI, it is sufficient to meet one of the criteria listed below:

1. Occurrence of at least one of the priority habitat type of Annex I HD, unless it representativeness has been assessed as 'not significant'.

2. Occurrence of at least one habitat type of Annex I HD, which is listed in Poland among the most endangered and occurring in a few places only, unless its occurrence has been assessed as 'not significant'.

3. Occurrence of at least one type of habitat listed in Annex I HD, if its area calculated as proportion of the national territory exceeds $2 \%$.

4. Occurrence of at least one of the priority species listed in Annex II HD, unless its presence has been assessed to be 'not significant'.

5. Occurrence of at least one of the priority species listed in Annex II HD, which is among the most endangered in Poland (Red List categories CR and EN) and has small number of stations, unless its presence has been assessed to be 'not-significant'. 
6. Occurrence of at least one of the species listed in Annex II HD, unless its population number in the site, compared with the whole population number in the national territory exceeds $2 \%$.

7. Occurrence of at least one of the species listed in Annex II HD, when the global assessment of the value of a given site is 'excellent' or 'good'.

8. Occurrence of a higher number ( $>5)$ of habitat types listed in Annex I HD and/or species listed in Annex II HD when the global assessment of the site for each of these parameters is at least 'significant.'

Applying criteria 1 and 4 (occurrence of priority natural habitat types and priority species) does not raise doubts and can be easily justified. These are habitats and species particularly endangered on European scale the Community bears particular responsibility for their conservation. For this reason, the Member States should, in the first place, strive to secure sites for their conservation. Thus, unless their occurrence on the national scale has not been assessed as 'not-significant presence', these should be considered as potential SCIs. The criteria pertaining to the occurrence of habitat types and species which are among the most endangered and have only few stations within Poland (criteria 2 and 5) might be more disputable. In the HD, however, the rarity or the level of danger to a habitat type or species is considered in the context of the EU territory, and - more specifically - of the biogeographical regions distinguished within the EU. The Member States should approach the selection of sites for each habitat type and for each species listed in Annexes I and II with equal care (and attach the utmost attention to priority ones). Moreover, when the resources of a given species or a habitat type are significant in a particular country (which means that they are not endangered and/or rare there), their representation in the Natura 2000 network should also be strong (Article 3, para 2 of the HD). Nevertheless, the suggested criterion seems to be useful because it combines the European 'interest' with the national one, and guarantees that within the sites of essential importance to the protection of the rarest and most endangered sites and species of European importance within that country are selected at the initial stage of work. The selection of such habitat types and species is a separate issue. In order to minimize the subjectivism associated with the selection, the entire procedure should be based on a well-defined and widely accepted classification. The most suitable sources might be the newest editions of Red Books and Red Lists as the determinants of the current status of species in the country implementing the Natura 2000 network. When the relevant red lists for habitat types are not available, one must rely on the knowledge of experts.

Criteria 3 and 6 pertain directly to the estimates required in the Standard Data Forms used for the required description of proposed sites. We assumed that either the size of the surface covered by a particular habitat type within the selected site exceeding $2 \%$ of the total surface of the habitat within the country, or the population number exceeding $2 \%$ of the total population number in Poland (cf. criteria referred to in Annex III, Stage $1 \mathrm{Ab}$ and 1Ba), are sufficient grounds for indicating the site as valuable for the purposes of the Natura 2000 network. These criteria follow chiefly from our experience gathered during the work of a group of experts dealing with the analysis of distribution of habitat types and species in Poland. For a remarkable proportion of these habitat types and species, the dispersion of their locations in the country is so high, that any concentration above $2 \%$ deserves consideration for the purposes of the network. 
The next criterion (7) pertains to the global assessment of the site for species of Annex II. It seems that any case when this assessment is 'excellent' or 'good' the site has enough value to be included in the proposals for the network. These high assessments of the value for species were based chiefly on the objective criterion of the relative size of population and given only when has been relevant information available; thus may be trusted. This criterion, however, has no matching criterion for habitat types. The analysis of the global assessment of the value of sites from the viewpoint of their suitability to habitat conservation performed on the data from Stage I of the work on network development in Poland, have yielded most results at 'excellent' and 'good' ranks. In such a case, the importance of the evaluation as a criterion vanishes. We believe that the reason for the domination of top evaluations for habitat types stems from two reasons: (1) the basic component of the evaluation is the representativeness of the habitat type, i.e. a subjective judgement and (2) the state of conservation of habitats in Poland is still relatively good.

The last criterion (8) pertains to biodiversity in a site under consideration. We have assumed arbitrarily that if a site has not met any of the earlier criteria, the presence of at least 5 natural habitats and/or species of European interest (Annexes I and II HD), is sufficient to designate it as pSCI, provided that the global assessment for each of them is at least 'significant'. This criterion shall facilitate the selection of pSCI in these countries which lack comprehensive inventories of the resources of nature, and where the information on the occurrence of species and habitat types is thus limited to the mere finding of their presence.

\section{What kind of criteria could be most useful?}

The procedure of identification and designation of the SAC, i.e. sites important for conservation of habitat types and species (except for birds), is much more complex than in the case of selecting Special Protected Areas (SPAs) - sites important for conservation of birds - the other component of the Natura 2000 network (Fig. 1). The reasons behind it are just the criteria applied at national level to select SAC (or rather pSCI) and SPAs. In case of SPAs, the selection requires accurate qualitative-quantitative criteria, based on the criteria adopted by BirdLife International elaborated for the identification of Important Bird Areas (Heath, Evans, 2000; Gromadzki et al., 2002; Jackson et al., 2004). This greatly simplifies the selection process for SPAs, as the proposals submitted by Member States, when meeting specific criteria, are accepted automatically by the European Commission (Fig. 1). The situation is different in the case of sites designated under the HD. As the criteria for their selection at the national level rely chiefly on expert judgement, subjective as it is, the experts of the European Commission reserve the right to assess whether the sites submitted are indeed of Community importance. The question arises whether applying solely the criteria recommended in Annex III HD can lead to the selection by national experts of a pool of sites which will satisfy the Commission (we leave out of consideration the officially submitted national lists whose composition may depend much on non-substantive modalities, such as resistance from various interest groups, landowners etc). Above all, it seems that in the case of countries with relatively well preserved nature, applying these criteria may lead to selecting high numbers of sites, covering such large proportion of national territory, that their designation may be 


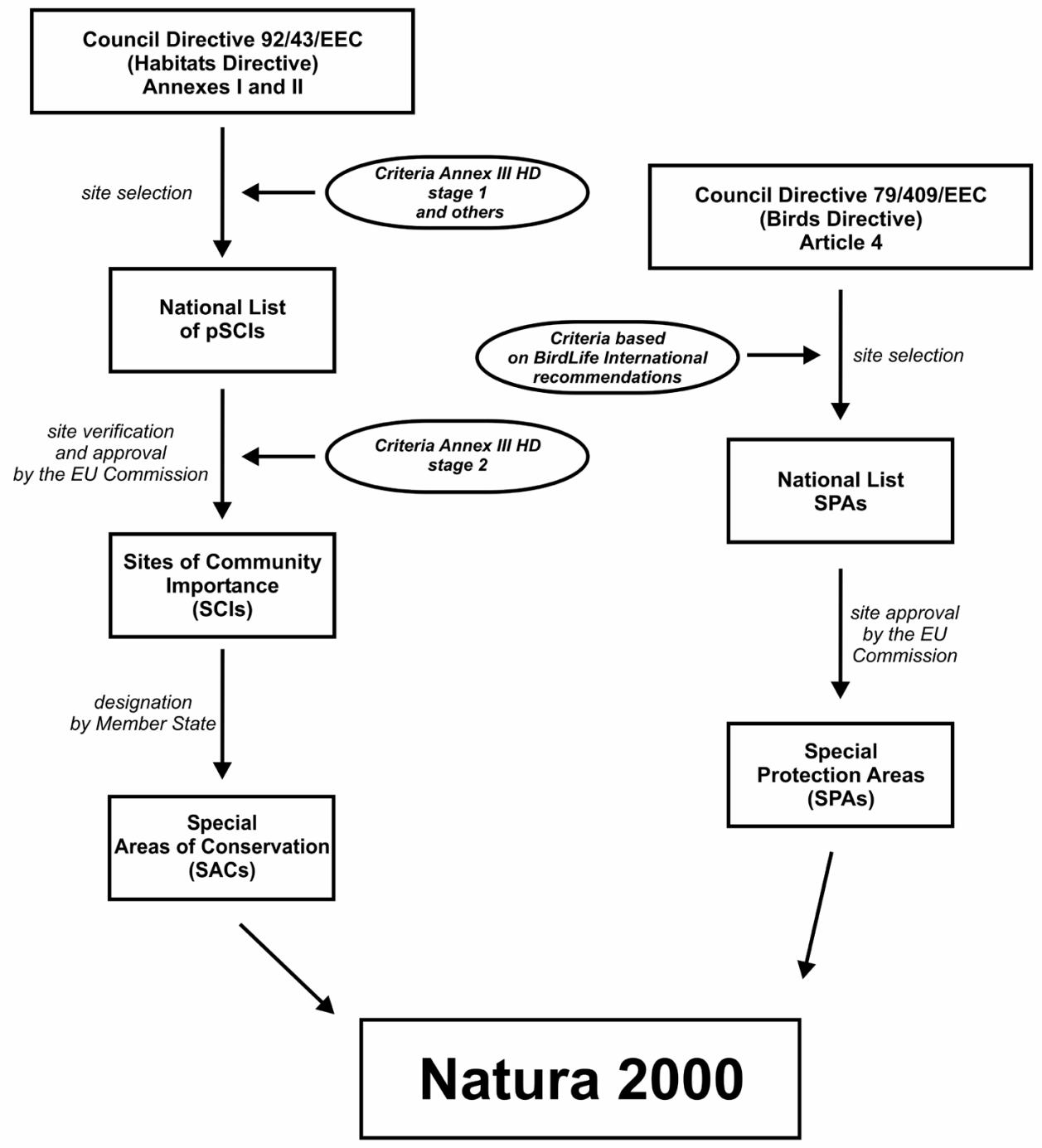

Fig. 1. Building Natura 2000 network: differences in designation procedures for SACs and SPAs resulting from the criteria applied.

unrealistic because of economic considerations. At this point it should be reminded that the $\mathrm{HD}$ does not require the conservation of all sites where habitat types and species listed in Annexes I and II occur; but nevertheless assumes that a suitable 'representation' thereof will be secured in the Natura 2000 network in proportion to national resources of these habitat types and species (Article 3.2 HD). But the HD does not indicate any specific criteria recommended for the purpose. The Member States may thus bypass the issue of suitable represen- 
tation of habitat types and species in their proposals to the network and wait for the assessment by the Commission, or to determine themselves the proportion of national resources of suggested habitat types or species should be included in the proposed network to consider them sufficiently protected. Depending on a habitat type or a species and the magnitude of its national resources, this value may even reach $100 \%$. The experience of the Member States indicates that the European Commission refuses to approve the proposals which secure less than $20-30 \%$ of the national resources of specific types of habitats, and of species; in the case of priority habitats and species this threshold might be even higher (Criteria, 2002). In the face of unknown resources of a specific habitat type or a species (this situation occurs quite often when there is no inventory made in a given country) any arbitrary presumption as to the proportion which should be protected in the Natura 2000 network could not be implemented in practice thus there is no sense to make such presumption whatsoever.

Another problem is connected with the evaluation performed by the European Commission's experts of the importance to the Community of sites submitted by a Member State. This importance is considered more in the categories of biogeographical regions distinguished in the Community rather than of the latter as a whole. So there is somewhat significant incoherence between the criteria for selecting pSCI recommended in Annex III HD and the expected result of that selection. The sites should be important to the conservation of a habitat type or a species, considered on the scale of a biogeographical region but at the same time the recommended criteria refer to their importance at the national level.

Our experience of selecting pSCI at national level indicates that this stage of work calls for more precise criteria than these recommended in the HD. Creating for SAC the analogous set of criteria as that which exists for SPAs, is unlikely because of the complex nature of groups of species covered in the HD (mammals, reptiles, amphibians, fishes, invertebrates, and plants) as well as because of the specific features of the HD connected with classification of natural habitat types. It is nevertheless worthy to search for some other, additional solutions, based on the requirements set out in the HD. It is important to remember that the additional criteria should be clearly defined, i.e. easy to apply not only by a narrow group of experts, but also by a wider group of interested persons. We try to include this aspect by proposing more unambiguous criteria and then testing them in our co-operation with the VITs responsible for the regional proposals of sites for network in Poland. The results of this effort indicate that the criteria have helped in the selection. We also know from the VITs members that the problems in applying the criteria had more to do with insufficient knowledge of specific natural values (habitat types and species) in the sites and the ensuing difficulties in implementing some assessments rather than too 'general' nature of the criteria themselves. The experts - even the best ones - differ in judging e.g. the representativeness of the same habitat type patch or the state or perspectives of its conservation within one and the same area - something that we experienced when verifying Polish proposals of pSCI. For this reason, it is still worthwhile to work on improving the criteria for their selection. This issue is of prime important to the new EU Member States which are still at the initial stages of implementing the network. However, because Natura 2000 is an open network, the issue of criteria will remain open at each stage of the work, including the verification of sites which have already been included in the network. 


\section{Acknowledgements}

We thank Marek Baranowski, Joanna Perzanowska, Wojciech Mróz, Andrzej Weigle, Jan Wróbel and Katarzyna Zając for many fruitful discussions on the criteria. This work was also improved by stimulating comments of the members of the VITs. The study was supported by the Polish Ministry of Environment (contract No 989/2001/ Wn50/NE-PR-TX/D).

\section{References}

Baranowski, M. (2003). Work on the Natura 2000 network in Poland (in Polish). In M. Makomaska-Juchiewicz \& S. Tworek (eds.), Ekologiczna Sieć Natura 2000: problem czy szansa? (pp. 219-227). Kraków: IOP PAN.

Council Directive 92/43/EEC on the Conservation of Natural Habitats and Wild Flora and Fauna (The Habitats Directive).

Council Directive 79/409/EEC on the Conservation of Wild Birds (The Birds Directive).

Criteria for assessing national lists of pSCI at biogeographical level. DG Environment, document Hab.97/2 rev. 4 (13.5.2002).

Dimitrakopoulos, P.G., Memtsas, D. \& Troumbis A.Y. (2004). Questioning the effectiveness of the Natura 2000 Special Areas of Conservation strategy: the case of Crete. Glob. Ecol. Biogeogr., 13, 199-207. DOI: 10.1111/j.1466822X.2004.00086.x.

Interpretation Manual of European Union Habitats - EUR 25, April 2003. European Commission DG Environment. Nature and Biodiversity.

Głowaciński, Z. (Ed.) (2001). Polish Red Data Book of Animals. Vertebrates (in Polish). Warszawa: PWRiL.

Głowaciński, Z. (Ed.) (2002). Red list of threatened animals in Poland (in Polish). Kraków: Instytut Ochrony Przyrody PAN.

Gromadzki, M., Błaszkowska, B., Chylarecki, P., Gromadzka, J., Sikora, A., Wieloch, M. \& Wójcik B. (2002). Network of bird areas in Poland. Implementation of the Council Directive on the Conservation of Wild Birds (in Polish). Gdańsk: Ogólnopolskie Towarzystwo Ochrony Ptaków.

He, F.L. \& Legendre P. (2002). Species diversity patterns derived from species-area models. Ecology, 83, 11851198. DOI: 10.1890/0012-9658(2002)083[1185:SDPDFS]2.0.CO;2.

Heath, M.F. \& Evans M.I. (Eds.) (2000). Important Bird Areas in Europe: Priority sites for conservation. Cambridge: BirdLife International (BirdLife Conservation Series No. 8).

Herbich, J. (Ed.) (2004). Manuals of Natura 2000 habitat types and species conservation (in Polish). Vol. 1-4. Warszawa: Wyd. Ministerstwo Środowiska.

Jackson, S.F., Kershaw, M. \& Gaston K.J. (2004). The performance of procedures for selecting conservation areas: waterbirds in the UK. Biol. Conserv., 118, 261-270. DOI: 10.1016/j.biocon.2003.09.004.

Kaźmierczakowa, R. \& Zarzycki K. (Eds.) (2001). Polish Red Data Book of Plants (in Polish). Kraków: Instytut Botaniki im. W. Szafera PAN, Instytut Ochrony Przyrody PAN.

Makomaska-Juchiewicz, M. \& Tworek S. (eds.) (2003). Natura 2000 Ecological Network: a problem or a chance? (in Polish). Kraków: IOP PAN.

Rojas-Briales, E. (2000). Socio-economics of nature protection policies in the perspective of the implementation of Natura 2000 Network: the Spanish case. Forestry, 73, 199-207. DOI: 10.1093/forestry/73.2.199.

Rosenzweig, M.L. (1995). Species diversity in space and time. Cambridge: Cambridge University Press.

Schluter, D. \& Ricklefs R.E. (Eds.) (1993). Species diversity in ecological communities. Historical and geographical perspectives. Chicago, London: University of Chicago Press. 